\title{
Full Cell Parameterization of a High-Power Lithium-Ion Battery for a Physico-Chemical Model: Part II. Thermal Parameters and Validation
}

\author{
Johannes Schmalstieg ${ }^{1,2}$ and Dirk Uwe Sauer ${ }^{1,2,3,4, \mathrm{z}}$ \\ ${ }^{I}$ Electrochemical Energy Conversion and Storage Systems Group, Institute for Power Electronics and Electrical Drives \\ (ISEA), RWTH Aachen University, 52066 Aachen, Germany \\ ${ }^{2}$ Jülich Aachen Research Alliance, JARA-Energy, Germany \\ ${ }^{3}$ Institute for Power Generation and Storage Systems (PGS), E.ON ERC, RWTH Aachen University, Aachen, Germany \\ ${ }^{4}$ Helmholtz Institute Münster (HI MS), IEK-12, Forschungszentrum Jülich, 48149 Münster, Germany
}

\begin{abstract}
Physico-chemical models allow a deep view into the internal processes and states of lithium-ion batteries. A crucial part of such models is the correct parameterization of the cell under consideration. In the first part of this publication methods to determine physical and electrochemical parameters are described and the experimental results from a PHEV cell are given. As the cell shows significant self-heating, a simple thermal model is introduced and the thermal parameters of the cell are determined. After a summary of all identified parameters a validation of these input data and the model is given. A wide range of measurements is compared to simulation results. This includes discharges at different temperatures and current rates as well as pulse tests and a realistic driving profile.

(C) The Author(s) 2018. Published by ECS. This is an open access article distributed under the terms of the Creative Commons Attribution 4.0 License (CC BY, http://creativecommons.org/licenses/by/4.0/), which permits unrestricted reuse of the work in any medium, provided the original work is properly cited. [DOI: 10.1149/2.0331816jes]

(cc) BY
\end{abstract}

Manuscript submitted October 3, 2018; revised manuscript received November 12, 2018. Published December 10, 2018

Physico-chemical models are an effective method for understanding lithium-ion batteries as they allow access to internal states. These internal states are very important for the operation of lithium-ion batteries, especially under extreme conditions. For example, it is mainly the local anode potential, which contributes to the calendar battery aging via SEI formation and which is of crucial importance for the occurrence of lithium plating.

The battery simulation by modeling of porous electrodes was already introduced by Newman in $1975 .{ }^{1}$ Since then many works based on this have been published..$^{2-10}$ However, the parameterization of these models to a specific battery is of crucial importance for realistic simulation results. This includes a variety of material parameters, from the electrolyte, the active material or the porous structure. In almost all publications, however, it is not worked with specific cells, but instead parameters from many different sources are used. Or it is attempted to extract the parameters from the overall cell behavior using nonlinear fits. The full parameterization of commercial cells is so far only rarely described in the literature, for example by Refs. 11, 12 for a high-energy pouch cell. This publication adds a prismatic high-performance cell for PHEV applications.

This work is an translated excerpt from the German language $\mathrm{PhD}$ thesis Ref. 13. In the first part of this publication, ${ }^{14}$ methods for determining the individual material parameters were described and the respective results from the measurement of the given cell were presented. However, as the cell shows non-negligible self-heating, the thermal properties must also be simulated. In this second part of the publication, the extension of the standard Newman model by a simple thermal model is described. The Newman model itself is not repeated here again, since it is already described sufficiently in numerous other publications. Then the determination of the necessary thermal parameters is explained. A large number of validation profiles are used to validate the fully parameterized model under different conditions. First, an overview of all profiles is given before the comparison between simulation results and measurements is discussed individually.

\section{Thermal Model}

A simple thermal model is implemented to take the self-heating of the cell into account. It calculates the heat generation in the cell as well as the heat dissipation to the environment. Due to the low influence of the reversible heat, this effect is not considered further. Since no precise information about the thermal properties of the cell is known, the model is limited to describe the cell as an assembly of a coil (jelly roll) and a housing. The heat generation causes an increase in the temperature of the coil, from which heat is conducted to the housing and from there to the ambient air. The temperature $T_{\text {coil }}$ is then calculated by:

$$
\frac{\mathrm{d} T_{\text {coil }}}{\mathrm{d} t}=\frac{1}{C_{\text {coil }}} \cdot\left(\dot{Q}_{\text {generated }}-\dot{Q}_{\text {dissipated }}\right)
$$

Here $C_{\text {coil }}$ is the heat capacity of the coil and $\dot{Q}_{\text {generated }}$ as well as $\dot{Q}_{\text {dissipated }}$ are the heat produced in the cell or the heat dissipated from the coil.

To calculate the heat generation, all processes must be considered which lead to a deviation of the terminal voltage from the open-circuit voltage. For this purpose three sources for heat regeneration $\dot{Q}_{\text {generated }}$ are used in the model:

$$
\dot{Q}_{\text {generated }}=\dot{Q}_{\text {resistance }}+\dot{Q}_{\text {electrolyte }}+\dot{Q}_{\text {particle }}
$$

In this context $\dot{Q}_{\text {resistance }}$ is the heat generated at resistors of the electric network describing the current distribution in the model. This represents the electrical and ionic resistance in the active mass and electrolyte, but also the charge transfer reaction by the Butler-Volmer resistor. $\dot{Q}_{\text {electrolyte }}$ is the heat generated by the polarization of the electrolyte, $\dot{Q}_{\text {particle }}$ represents the polarization of the active material particles. Heat generation at physical models is considered also by Refs. 15 and 16, there however the heat arising in particles is not considered, but instead reversible heat

Even if some of the reactions may not be instantaneous heat generation in the physical sense, but e.g. the buildup of an gradient, whose degradation later leads to a heat generation, the calculated heat values are directly added to the current time step. This is mainly due to the clearly simplified handling, which does not require consideration of the individual heat generation mechanisms and their time constants, which are largely unknown. This only results in a temporal shift of the generated heat, the total amount of heat does not change. The resulting deviations are very small due to the high thermal capacities.

The individual contributions are calculated as following:

$$
\dot{Q}_{\text {resistance }}=R \cdot I^{2}
$$

The resistive heat is calculated trivially from the resistance $R$ of the electrical network resulting from the state of the 
physico-electrochemical conditions and the current $I$ flowing through it. This is done in the model for the current collector resistance, the electrical conductivity in the active material and the ionic conductivity in the electrolyte, as well as for the charge transfer resistance calculated via the Butler-Volmer equation.

The additional heat generated in the electrolyte by the concentration gradient is calculated using the diffusion voltage $U_{\text {diffusion }}$ already present in the electrical network, multiplied by the current $I$ through this electrolyte range.

$$
\begin{aligned}
\dot{Q}_{\text {electrolyte }} & =U_{\text {diffusion }} \cdot I \\
& =\frac{2 \cdot R \cdot T}{F} \cdot\left(0.5-t_{0}^{+}\right) \cdot \ln \left(\frac{c_{\mathrm{e}, i+1}}{c_{\mathrm{e}, i}}\right) \cdot I
\end{aligned}
$$

$R$ is the general gas constant, $T$ the absolute temperature, $F$ the Faraday constant and $t_{+}$the transfer number for lithium in the electrolyte. $c_{\mathrm{e}, i}$ and $c_{\mathrm{e}, i+1}$ are the electrolyte concentrations of the two volume elements between which the voltage is calculated.

The heat generated in the particle is calculated from the difference of the active material open circuit voltage $U_{\mathrm{OCV}}$ for the lithium concentration at the particle surface $\delta_{\text {surface }}$ and the averaged lithium concentration in the particle $\delta_{\text {averaged }}$ multiplied by the intercalation current $I$. In addition, the voltage deviation $U_{\text {Nernst }}$ caused by concentration changes in the electrolyte is also taken into account.

$$
\begin{aligned}
& \dot{Q}_{\text {particle }}= {\left[U_{\mathrm{OCV}}\left(\delta_{\text {surface }}\right)-U_{\mathrm{OCV}}\left(\delta_{\text {averaged }}\right)\right] \cdot I+U_{\text {Nernst }} \cdot I } \\
& \text { with } \quad U_{\text {Nernst }}=\frac{R \cdot T}{z \cdot F} \cdot \ln \left(\frac{c_{\mathrm{e}}}{c_{\mathrm{e}, \text { ref }}}\right)
\end{aligned}
$$

Due to the calculation method, negative values can occur when calculating the heat generation of electrolyte and particles. This happens when the current direction is reversed shortly after the buildup of large concentration gradients. As long as the concentration gradient has not disappeared or is rebuilt in the opposite direction, only the sign of the current changes and a negative heat is generated. This initially very unphysical fact is a direct consequence of the calculation method, which allows the heat to be generated directly in the time step of the voltage deviation. If a concentration gradient is built up, the heat generated by the gradient and its relaxation is directly included. However, if the gradient does not degrade by normal relaxation but is actively reduced by an inverse current, the anticipated heat of the relaxation phase must be removed. This leads to short negative heat generation.

The heat $\dot{Q}_{\text {dissipated }}$ transferred from the coil to the housing is modeled by simple heat conduction.

$$
\dot{Q}_{\text {dissipated }}=\lambda_{\text {coil-housing }} \cdot\left(T_{\text {coil }}-T_{\text {housing }}\right)
$$

$\lambda_{\text {coil-housing }}$ is the thermal conductivity between the coil and housing that has to be determined experimentally. The heat conduction from the housing to the ambient air is calculated analogously.

\section{Thermal Characterization}

The investigated cell shows a self heating during usage which cannot be neglected. During a full discharge with $5 \mathrm{C}$ in a temperature chamber (BINDER MK 240) at $25^{\circ} \mathrm{C}$, an increase of the surface temperature to $38.5^{\circ} \mathrm{C}$ was measured. The temperature of the active material of the coil was probably even higher. As the speed of several processes in the batteries, like the diffusion, is strongly depending on temperature, the self heating of the cell must be included in the model. In addition to the generated heat, the heat capacity and the heat dissipation must be known. The heat dissipation is strongly dependent on the environment of the cell and is therefore determined directly in the temperature chamber in which all verification measurements have taken place. A strong fan is installed in the chamber for an even temperature distribution, so the values determined in this way cannot be transferred directly to other ambient conditions. The heat capacity is determined by adjustments of thermal simulations to existing measurements.

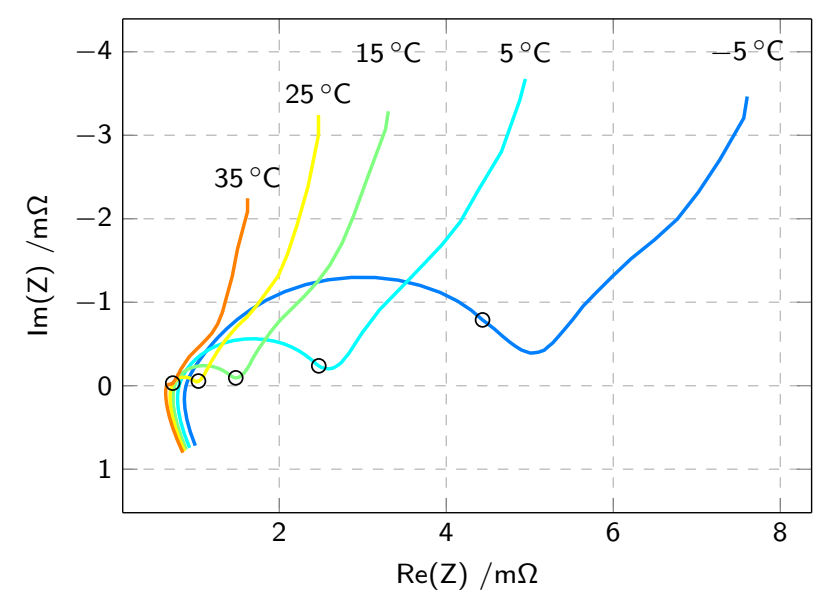

Figure 1. Nyquist plot of EIS measurements on the full cell at approx. 50\% SOC and different temperatures. For each temperature the $1 \mathrm{~Hz}$ point is marked.

To determine the thermal conductivity, the temperature inside and outside the battery must be known. However, since the battery does not contain a temperature sensor, as it is a normal commercial cell, the temperature must be determined indirectly. Therefore, the temperature dependence of the battery reaction itself is used, as it can be seen in Electrochemical Impedance Spectroscopy (EIS) measurements shown in Figure 1. Schmidt et al. ${ }^{17}$ showed that even with inhomogeneous temperature distributions the average cell temperature can be determined well by means of EIS measurements. In Ref. 18 thermal simulations of a battery similar to the cell under investigation are shown. There, at a maximum temperature difference of $10^{\circ} \mathrm{C}$ to the ambient the temperature gradient of the coil is lower than $3.6^{\circ} \mathrm{C}$, large parts of the coil have a very homogeneous temperature.

Since no impedance spectroscope was available at the test circuit used for the verification, pulse resistances were used instead. A pulse length of $1 \mathrm{~s}$ was chosen in consideration of a high resistance change over the temperature and a short measuring duration. The pulse current was $1 \mathrm{C}$, with a positive and a negative pulse to keep the SOC and a pause of $1.5 \mathrm{~s}$ in between. All measurements were made at a SOC of $50 \%$.

To determine the temperature dependency, the cell in the temperature chamber was tempered from $-5^{\circ} \mathrm{C}$ to $50^{\circ} \mathrm{C}$, in steps of $5^{\circ} \mathrm{C}$. For a complete homogenization of the battery temperature, each temperature was kept at least $2 \mathrm{~h}$. During the entire measurement a resistance determination was made every minute. The course of the measurement is shown on the left in Figure 2 . The resistance $R_{1 \mathrm{~s}}$ was calculated by:

$$
R_{1 \mathrm{~s}}=\frac{U_{\text {pulse, end }}-U_{\text {pulse, start }}}{I_{\text {pulse }}}
$$

An averaging of the charging and discharging pulse as well as a sliding average value over 5 data point have been applied in the graph. The relationship between the battery temperature and the internal resistance, derived from the measurement, is shown as an Arrhenius plot on the right in Figure 2. It is clear that the temperature dependence does not correspond exactly to the Arrhenius equation, as also a temperature-independent resistance is present. This is presumably the ohmic resistance of the contacts and the current collectors. The total resistance $R_{1 \mathrm{~s}}$ can be defined by:

$$
R_{1 \mathrm{~s}}=R_{T} \cdot \exp \left(-\frac{E_{\mathrm{A}}}{R \cdot T}\right)+R_{0}
$$

Where $R_{T}$ is a temperature depending part of the resistance, $E_{\mathrm{A}}$ is the activation energy, $R$ is the universal gas constant, $T$ is the absolute temperature and $R_{0}$ is the temperature independent contact and current collector resistance. The optimal value for $R_{0}$ is determined by fitting to $0.534 \mathrm{~m} \Omega$. The temperature-dependent pulse resistance remaining 

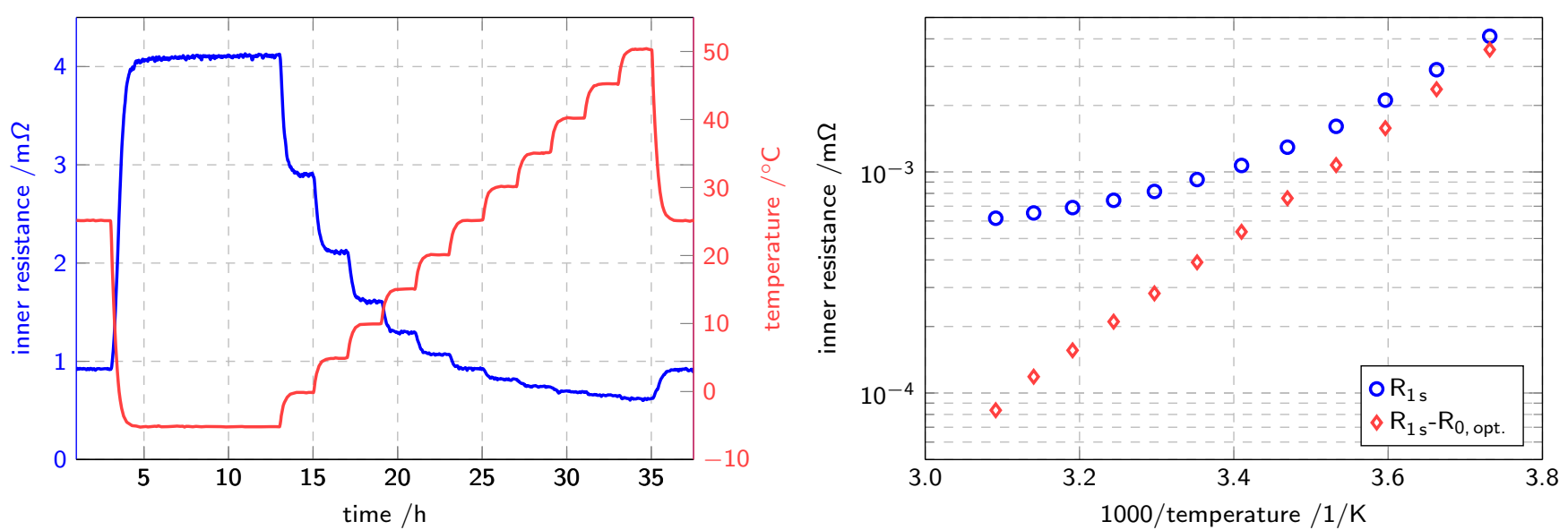

Figure 2. Resistance and cell case temperature during the calibration (left). Arrhenius plot of the total internal resistance and a temperature depending part, which is calculated by subtracting a temperature independent part $R_{0, \text { opt. }}=0.534 \mathrm{~m} \Omega$ (right).
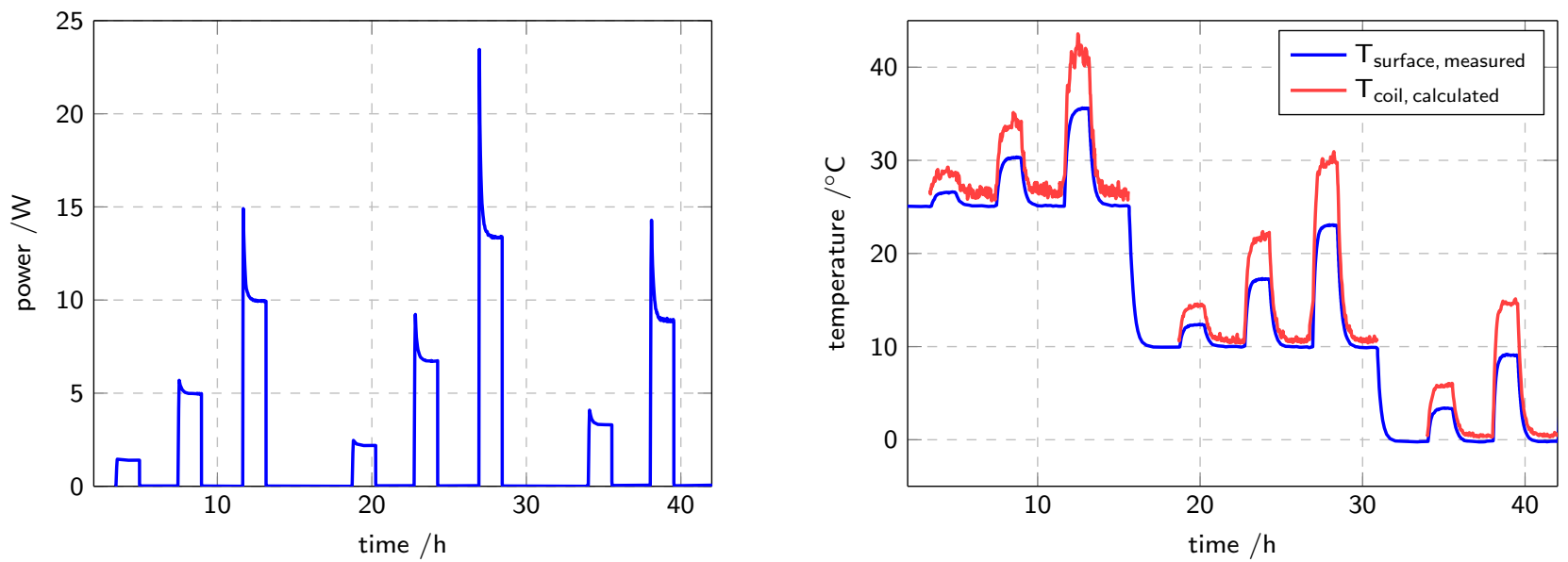

Figure 3. Input power (left) as well as measured housing temperature and calculated coil temperature (right) over time.

after subtraction of $R_{0}$ is also shown in Figure 2 (right), resulting in a very good temperature dependence according to Arrhenius. In the literature the contact resistance between electrode and current collector is given with $0.105 \mathrm{~m} \Omega \mathrm{m}^{2}$ to $0.755 \mathrm{~m} \Omega \mathrm{m}^{2},{ }^{19}[\mathrm{p} .143]$ and $5.1 \times 10^{-3} \mathrm{~m} \Omega \mathrm{m}^{2}$ (graphite) as well as $2.79 \mathrm{~m} \Omega \mathrm{m}^{2}$ to $4.30 \mathrm{~m} \Omega \mathrm{m}^{2}$ (cathode). ${ }^{20}$ With respect to the electrode surface of each $1.7775 \mathrm{~m}^{2}$ this would result in resistances of $2.87 \times 10^{-3} \mathrm{~m} \Omega$ to $2.42 \mathrm{~m} \Omega$ per electrode. The here determined value of $0.534 \mathrm{~m} \Omega$ for both electrodes together and the current collector resistance seems therefore realistic.

To produce heat in the battery, it was heated by consecutively alternating positive and negative current pulses of $1 \mathrm{~s}$ duration. After each $110 \mathrm{~s}$ of heating a pause of $10 \mathrm{~s}$ was made for another current pulse to measure the temperature. At ambient temperatures of $25^{\circ} \mathrm{C}$, $10^{\circ} \mathrm{C}$ and $0^{\circ} \mathrm{C}$ pulses with currents of $50 \mathrm{~A}, 100 \mathrm{~A}$ and $150 \mathrm{~A}(150 \mathrm{~A}$ not at $0^{\circ} \mathrm{C}$ ) have been applied. The heat introduced by the pulses as well as the measured surface temperature together with the coil temperature calculated from the resistance are shown in Figure 3 and listed in Table I.

If the generated power, which is equal to the dissipated power for the stationary case, is plotted over the temperature differences between ambient, housing and coil, a clear linear relationships results. These are shown in Figure 4. A linear regression results in a total thermal conductivity from the coil to the ambient of $0.69 \mathrm{~W} / \mathrm{K}$. This stems from the series connection of the coil-housing thermal conductivity $(2.20 \mathrm{~W} / \mathrm{K})$ and the housing-ambient thermal conductivity $(1.01$ $\mathrm{W} / \mathrm{K})$.

In order to validate the thermal conductivities and to determine the thermal capacities, a thermal calculation is carried out on the basis of discharges at different currents and temperatures. For example discharge curves at $25^{\circ} \mathrm{C}$ with currents from $1 \mathrm{C}$ to $5 \mathrm{C}$ are shown in Figure 5. In order to estimate the losses in these discharges, a further discharge is plotted with $0.25 \mathrm{C}$ at $40^{\circ} \mathrm{C}$. Only very low losses are expected at these conditions due to the low current rate and high temperature. Therefore, this is used as reference curve.

To calculate the losses $P(t)$, the voltage difference between the discharge curve $U(t)$ and the reference curve $U_{\text {ref }}(t)$ is calculated and multiplied by the current $I$ :

$$
P(t)=\left[U(t)-U_{\mathrm{ref}}(t)\right] \cdot I
$$

\begin{tabular}{cccc}
\hline $\begin{array}{c}\text { Table I. Input power as } \\
\text { temperatures in steady state. }\end{array}$ & $\begin{array}{c}\text { well } \\
\text { as measured or }\end{array}$ & calculated \\
$\begin{array}{c}\text { Power } \\
\text { W }\end{array}$ & $\begin{array}{c}\text { Ambient temp. } \\
{ }^{\circ} \text { C }\end{array}$ & $\begin{array}{c}\text { Housing temp. } \\
{ }^{\circ} \text { C }\end{array}$ & $\begin{array}{c}\text { Coil temp. } \\
{ }^{\circ} \mathrm{C}\end{array}$ \\
\hline 1.40 & 25 & 26.6 & 28.5 \\
4.97 & 25 & 30.3 & 33.9 \\
9.94 & 25 & 35.6 & 41.0 \\
2.19 & 10 & 12.4 & 14.4 \\
6.72 & 10 & 17.3 & 21.9 \\
13.37 & 10 & 23.0 & 30.1 \\
3.30 & 0 & 3.4 & 5.9 \\
8.88 & 0 & 9.1 & 14.8 \\
\hline
\end{tabular}




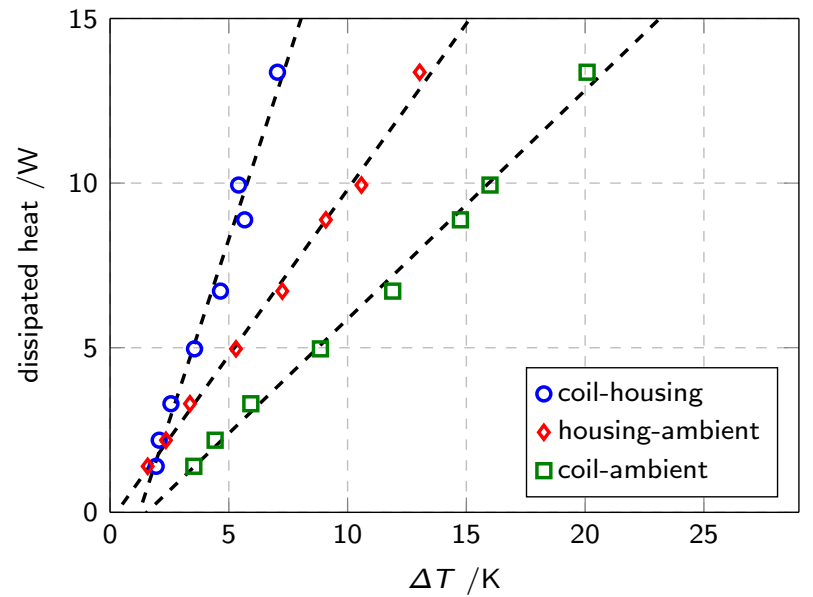

Figure 4. Heat dissipated over the temperature differences.

From the calculated power, a simple thermal model consisting of the coil inside the cell and the housing with the thermal capacities $C_{\text {coil }}$ and $C_{\text {housing }}$ as well as the thermal conductivities $\lambda_{\text {coil-housing }}$ from the coil to the housing and $\lambda_{\text {housing-ambient }}$ from the housing to the ambient, the temperature evolution over the discharge is calculated. The thermal conductivities are already known, the heat capacities are determined by an adaptation to the measured surface temperature. The temperature from coil $T_{\text {coil }}$ and housing $T_{\text {housing }}$ are calculated by:

$$
T_{\text {coil }}^{k+1}=T_{\text {coil }}^{k}+\frac{P^{k}-\left(T_{\text {coil }}^{k}-T_{\text {housing }}^{k}\right) \cdot \lambda_{\text {coil-housing }}}{C_{\text {coil }}}
$$

and

$$
\begin{aligned}
& T_{\text {housing }}^{k+1}=T_{\text {housing }}^{k} \\
& +\frac{\left(T_{\text {coil }}^{k}-T_{\text {housing }}^{k}\right) \cdot \lambda_{\text {coil-housing }}-\left(T_{\text {housing }}^{k}-T_{\text {ambient }}\right) \cdot \lambda_{\text {coil-housing }}}{C_{\text {housing }}}
\end{aligned}
$$

The superscript index $k$ refers to the time steps of the calculation. The calculation results in an optimum agreement with the measured housing temperatures for a heat capacity for the coil of $660 \mathrm{~J} / \mathrm{K}$ and of $150 \mathrm{~J} / \mathrm{K}$ for the housing. Despite the indirect determination, these values are in good agreement with the literature. Reference 18 gives a heat capacity of $975 \mathrm{~J} /(\mathrm{kg} \mathrm{K})$ for the coil, and $900 \mathrm{~J} /(\mathrm{kg} \mathrm{K})$ for aluminum. With the weight of the coil from approx $600 \mathrm{~g}$ and a housing weight of $160 \mathrm{~g}$ the calculated parameters result in similar values of $1100 \mathrm{~J} /(\mathrm{kg} \mathrm{K})$ and $937.5 \mathrm{~J} /(\mathrm{kg} \mathrm{K})$.

To illustrate the good agreement, the calculated housing temperatures are plotted over the measured value in the Figure 5 (right) for current rates from $1 \mathrm{C}$ to $5 \mathrm{C}$. This results in a clear straight line in the angle of $45^{\circ}$ with very slight deviations. Graphs with measured and simulated housing temperatures over time for different ambient temperatures can be found in section S.3 of the supplementary material.

\section{Parameter Summary}

Within the scope of the analysis almost all parameters of the examined cell could be determined. The comparison with literature values often showed a wide spread of the available data, due to the non-fixed overall system as well as the interaction of the individual components. This also illustrates the relevance of the determination of all parameters directly from the cell to be simulated compared to the pure collection of literature data, as is often done for simulations. In Table II all parameters for the physico-electrochemical simulation from the first part of the paper ${ }^{14}$ and the thermal analysis are summarized. A model validation is carried out in the next section using this data.

\section{Validation}

In this section the parameters measured before are used and simulations are carried out. For the validation, different load profiles have been measured, which are described first.

Validation profiles.-Various profiles were recorded to verify the parameterization. All validation profiles were performed on the full cells. For this purpose, a BNT 200-018-4 ME from Digatron was used for cycling. Every test was conducted at two cells simultaneously, with no relevant differences between the cells. All tests were carried out in a temperature chamber MK 240 from BINDER. During the measurement, current, voltage and housing temperature were recorded, the temperature was measured with a sensor at the center of the largest side surface.

The profiles used can be divided into two classes: Synthetic profiles for the assessment of individual parameters as well as a realistic profile for quantifying the deviations for later use. The synthetic profiles include discharge curves with variation of current and temperature as well as pulse tests, while the realistic profile relies on real driving data. The individual profiles are described below:

- The quasi OCV (qOCV) profile is based on a slow discharge and charge, each with $\mathrm{C} / 50$. Before there is a charge with $\mathrm{C} / 3$ and a
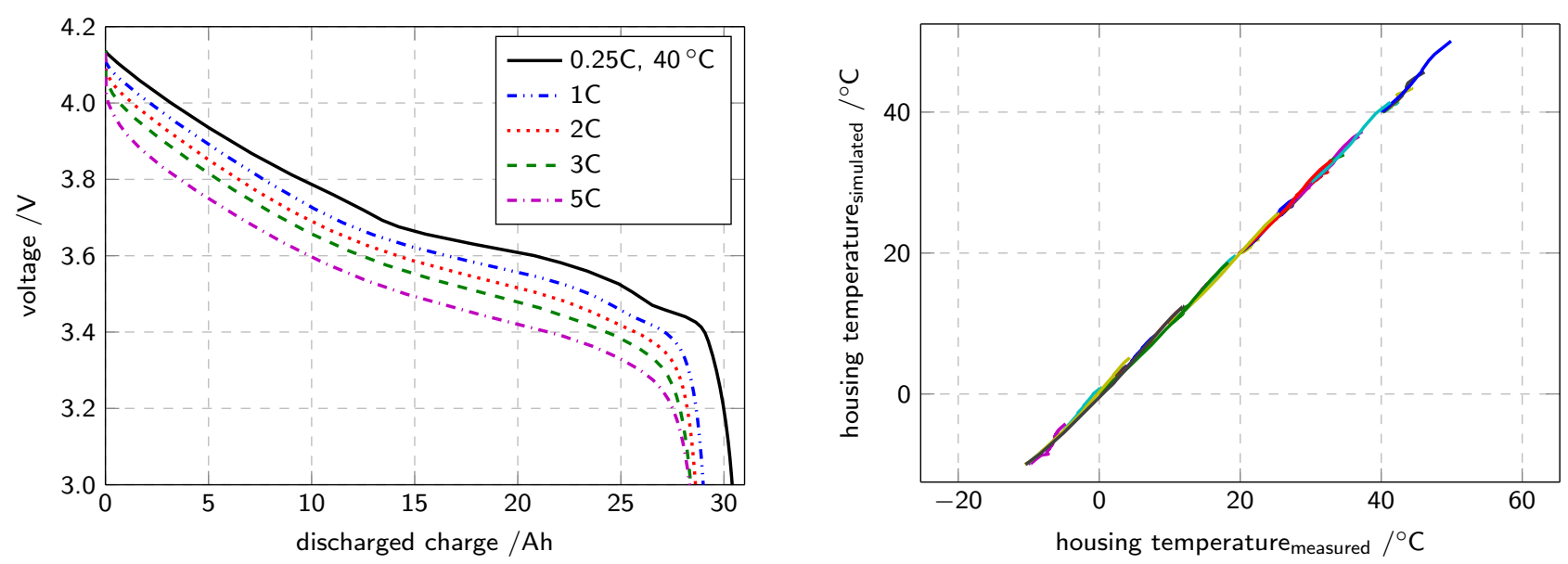

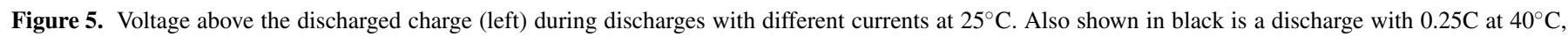
which is used as reference curve. Simulated housing temperatures above the measured temperatures (right) for currents between $1 \mathrm{C}$ to $5 \mathrm{C}$. 
Table II. Summary of all parameters for the physico-electrochemical simulation.

Neg. electrode

\section{Electrolyte solvent}

Conductive salt

Electrolyte conductivity

Electrolyte diffusion

Transference number

Active material

Porosity

Thickness

Bruggemann factor

Particle radius

OCV

Max. lithium concentration

Active material diffusion

Activation energy

Exchange current density

Activation energy

Double layer capacitance

Area

Active area

Volume fraction active mass

Electrode conductivity

Lithiation (0-100\% SOC)

Current collector resistance

Heat capacity

Heat conductivity

constant voltage $(\mathrm{CV})$ phase until C/50, followed by a two hour rest period. Between discharge and charge there is also a two hour rest period. This profile has also been used for the determination of the cell balancing.

- Discharges and charges are done at various current rates and temperatures. All tests start with of a standard charge $(\mathrm{C} / 3, \mathrm{CV}$ to $\mathrm{C} / 20$, at $25^{\circ} \mathrm{C}$ ) or a standard discharge $\left(1 \mathrm{C}\right.$, at $\left.25^{\circ} \mathrm{C}\right)$. The current rates for discharge are $1 \mathrm{C}$ to $5 \mathrm{C}$, each at $-10^{\circ} \mathrm{C}$ to $40^{\circ} \mathrm{C}$. Charging tests werde done with $0.25 \mathrm{C}$ to $2 \mathrm{C}$ also at $-10^{\circ} \mathrm{C}$ to $40^{\circ} \mathrm{C}$. Due to cell limitations, not all charging currents could be tested at low temperatures.

- The pulse profile consists of pulses with different current rates and lengths at various SOC. After a full charge $(\mathrm{C} / 3, \mathrm{CV}$ to $\mathrm{C} / 20)$ the cell is brought to $80 \%, 60 \%, 40 \%$ and $20 \%$ SOC with a discharge current of $0.5 \mathrm{C}$. At every SOC charge and discharge pulses with current rates of $0.25 \mathrm{C}, 0.5 \mathrm{C}, 1 \mathrm{C}, 2 \mathrm{C}$ and $5 \mathrm{C}$ and lengths of $10 \mathrm{~s}$ and $100 \mathrm{~s}$ are applied. The tests are conducted at ambient temperatures of $25^{\circ} \mathrm{C}, 40^{\circ} \mathrm{C}, 10^{\circ} \mathrm{C}$ and $-10^{\circ} \mathrm{C}$. At $10^{\circ} \mathrm{C}$ and $-10^{\circ} \mathrm{C}$, the 100 s pulses are limited to $1 \mathrm{C}$.
Separator/Electrolyte/Cell

Pos. electrode

$$
\begin{gathered}
\text { 1:1:1 EC/DMC/EMC (weight-\%) } \\
\text { LiPF }_{6} \\
\text { see Fig. 1 and eq. [1] in Ref. } 14 \\
\text { see eq. [2] in Ref. } 14 \\
0.26 \\
\\
39.49 \% \\
18.7 \mu \mathrm{m} \\
1.62
\end{gathered}
$$

$111 \mathrm{NMC}$

$20.9 \%$

$43.0 \mu \mathrm{m}$

1.44

$2.13 \mu \mathrm{m}$

see Fig. 5 (right) in Ref. 14

$48.39 \mathrm{~mol} / \mathrm{l}$

see eq. [14] in Ref. 14

$49.6 \mathrm{~kJ} / \mathrm{mol}$

$5.03 \times 10^{-4} \mathrm{~A} / \mathrm{cm}^{2}$

$78.1 \mathrm{~kJ} / \mathrm{mol}$

$0.198 \mathrm{~F} / \mathrm{m}^{2}$

$4 \times 375 \times 11.85 \mathrm{~cm}^{2}$

$4 \times 375 \times 11.85 \mathrm{~cm}^{2}$

$57.24 \%$

$0.1 \mathrm{~S} / \mathrm{cm}$

96.15-43.52\%

$0.534 \mathrm{~m} \Omega$

coil: $660 \mathrm{~J} / \mathrm{K}$

housing: $150 \mathrm{~J} / \mathrm{K}$

coil-housing: $2.20 \mathrm{~W} / \mathrm{K}$

housing-ambient: $1.01 \mathrm{~W} / \mathrm{K}$

- EIS measurementes are done at different SOC and temperatures. The measurements are carried out from $6 \mathrm{kHz}$ to $1 \mathrm{mHz}$ with a galvanostatic excitation, which is controlled to produce a voltage amplitude of $3 \mathrm{mV}$. Measurements were made at the interval of $5 \%$ SOC at temperatures of $25^{\circ} \mathrm{C}, 15^{\circ} \mathrm{C}$ and $5^{\circ} \mathrm{C}$. The tests were conducted using a Digatron BNT 100-006-12 ME coupled to a Digatron EISmeter.

- A realistic driving profile is used in the application oriented scenario. It consists of measurements done at our institute, including city and highway driving, with a resolution of one second. The profile is applied at ambient temperatures of $25^{\circ} \mathrm{C}, 40^{\circ} \mathrm{C}, 10^{\circ} \mathrm{C}$ and $-10^{\circ} \mathrm{C}$.

\section{Validation}

First the correct reproduction of the Open Circuit Voltage (OCV) as well as the cell balancing is checked. For this, the profile qOCV at $25^{\circ} \mathrm{C}$ is simulated and compared with the measurement. The plot of the measured and simulated voltage curve as well as the voltage deviation can be found in Figure 6.
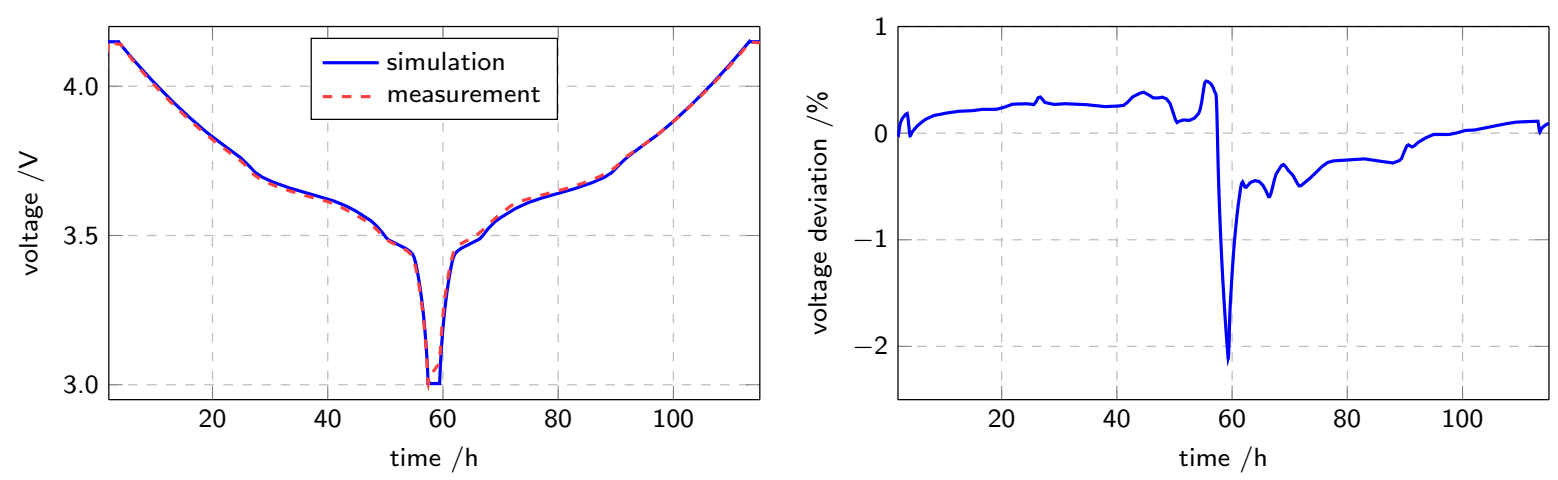

Figure 6. Comparison of measured and simulated voltage (left) and the percent deviation (right) for the qOCV profile. 

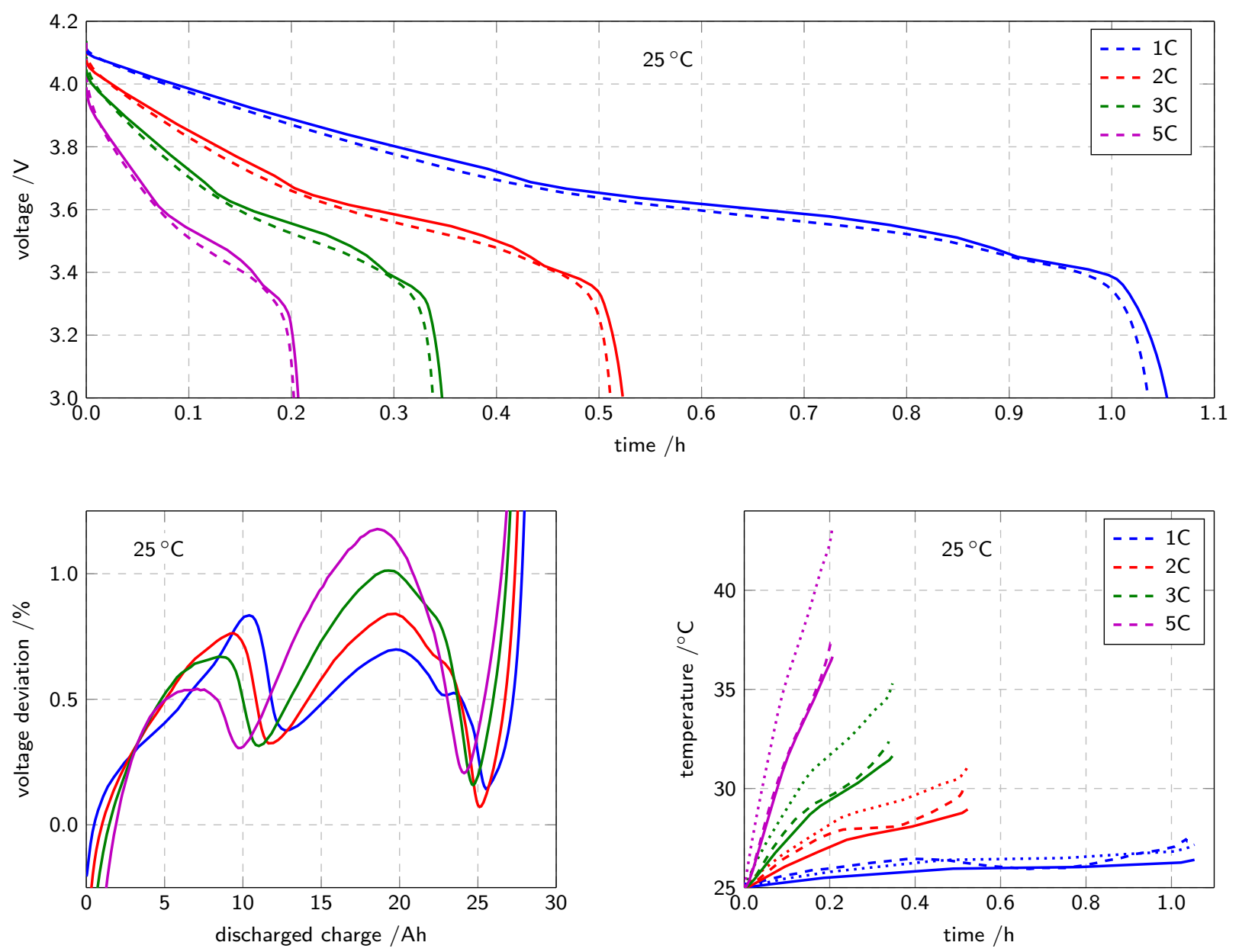

Figure 7. Comparison of the measured and simulated voltages (top) and temperatures (lower right) as well as the voltage deviations (lower left) for different discharge rates at an ambient temperature of $25^{\circ} \mathrm{C}$. The dashed lines represent the measurement, the solid lines are the simulation results. The temperatures refer to the housing temperature. The simulated temperatures of the coil are also plotted here as dotted lines.

There is a very good agreement between the simulation and the measurement. In wide ranges, the voltage deviation is under $\pm 0.5 \%$. Only in the range of the pause in the fully discharged state as well as at the very beginning of the charge is a more distinct deviation, which can be largely attributed to the differently fast relaxation during the break. The capacity of the cell also shows a very good correspondence between simulation and measurement. In the measurement, capacities of $29.86 \mathrm{Ah}$ for the discharge as well as 30.21 Ah for the charge were obtained. The simulation results in a capacity of $30.09 \mathrm{Ah}$ for both the discharge and charge. This corresponds to a deviation of only $0.78 \%$ and $-0.38 \%$. The difference between the charging and discharging capacity in the measurement is presumably due to the accuracy of the battery tests, which had to provide a current of only $0.56 \mathrm{~A}$ in this profile, but the smallest measuring range is $20 \mathrm{~A}$.

In the next step, the current dependency of the cell is considered. For this purpose, discharges with current rates of $1 \mathrm{C}, 2 \mathrm{C}, 3 \mathrm{C}$ and $5 \mathrm{C}$ are used. First, the measurements taken at an ambient temperature of $25^{\circ} \mathrm{C}$ are looked at in order to achieve the lowest possible influence of the temperature dependencies, although the cell temperature increases due to the self heating. In Figure 7 the comparisons of the cell voltages and the housing temperatures are shown. Here, too, a good reproduction of the discharge curve as well as of the extractable capacity is shown. The discharge capacity differs by $1.8 \%, 2.3 \%, 2.7 \%$ and $2.1 \%$ from the measured values. Also shown is the voltage deviation during the discharge. This is for all four discharge current rates in wide SOC ranges between $0 \%$ and $1 \%$, only the end of the discharge shows greater deviations in the voltage due to the slight temporal offset.
The housing temperature is well reproduced, the small deviations are probably due to the reversible heat, which is not simulated in the model.

The temperature dependency is tested using different ambient temperatures during discharge. These tests cover a wide temperature range with ambient temperatures of $-10^{\circ} \mathrm{C}$ to $40^{\circ} \mathrm{C}$ and are thus particularly sensitive to the temperature dependencies of all parameters. A comparison of the simulation results with the measurements is shown in Figure 8 at a discharge rate of 3C. A significant change over the temperature is now also visible in the extractable capacity of the simulation, as is also the case with the measurments. Overall, however, it is to be noted that the examined cell shows a very good performance under different ambient temperatures as well as at different current rates. It can be used without any problems in the full tested temperature and current range. The voltage deviations during the discharge, also shown in Figure 8 , is for all ambient temperatures over wide areas of the discharge under $\pm 1 \%$. The comparison of the simulated housing temperatures with the measured values shows a very good agreement with slight deviations at low ambient temperatures.

As an overview of all discharge tests carried out, the deviations of the extractable capacity for all ambient temperatures and discharge current rates can be found in Table III. A slight deviation of the simulation toward higher discharge capacities is shown for all test conditions. This indicates a loss mechanism that is parameterized too low in the simulation and leads to a too low overvoltage. Graphs with the voltage curves, voltage deviations and the temperature comparisons can be found for all test conditions in section S.4 of the supplementary material. 

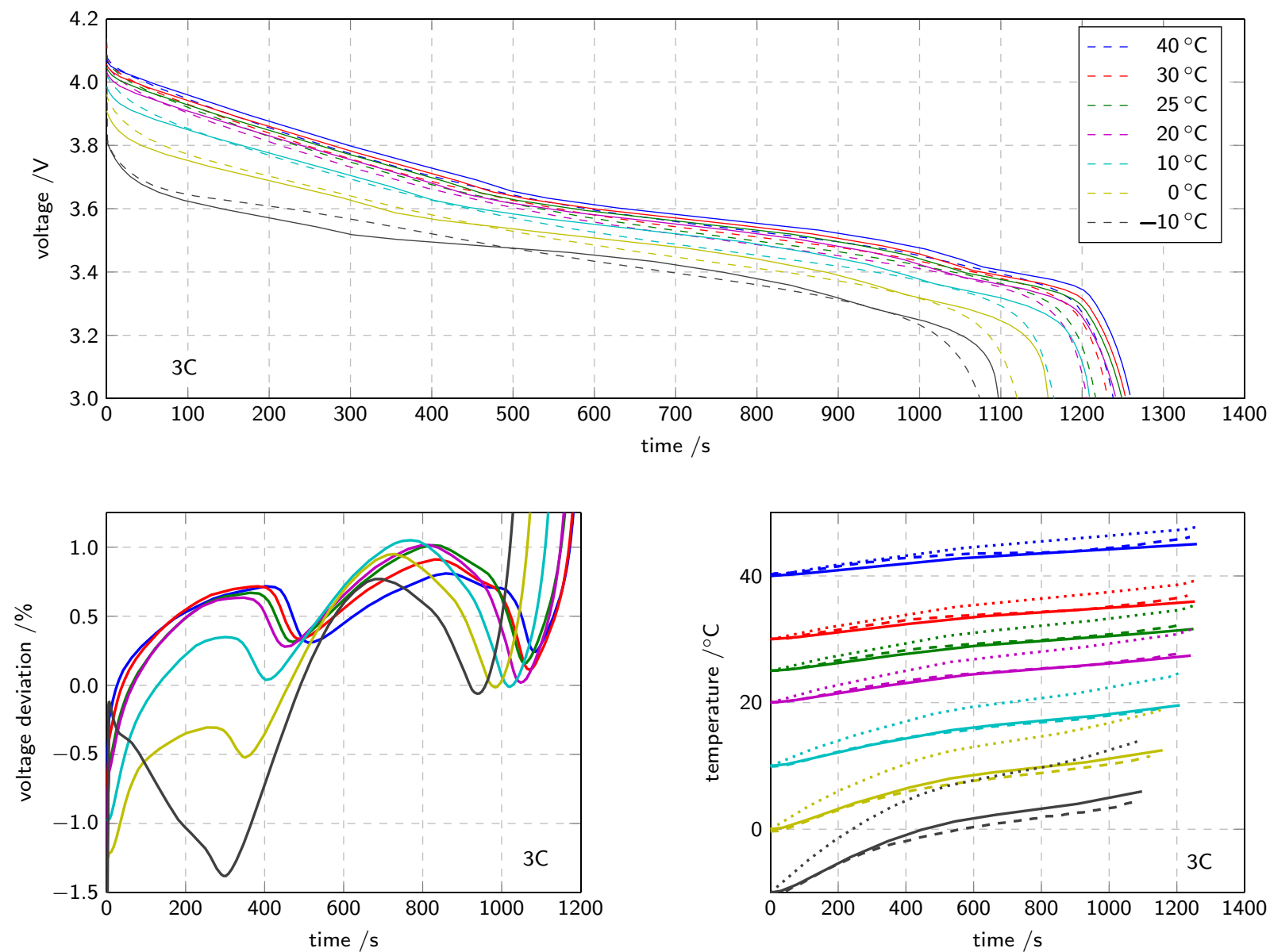

Figure 8. Comparison of the measured and simulated voltages (top) and temperatures (lower right) as well as the voltage deviations (lower left) for different ambient temperatures during discharges with $3 \mathrm{C}$. The dashed lines represent the measurement, the solid lines are the simulation results. The temperatures refer to the housing temperature. The simulated temperatures of the coil are also plotted here as dotted lines.

In addition to the discharge curves shown, similar tests were also carried out in the charging direction. Different ambient temperatures between $-10^{\circ} \mathrm{C}$ and $40^{\circ} \mathrm{C}$ and current rates between $0.25 \mathrm{C}$ and $2 \mathrm{C}$ were tested. Plots for the comparison of the voltages between simulation and measurements as well as the resulting voltage deviations are shown in section S.5 of the supplementary material for all test conditions, in addition there is also a table on the capacity deviations of the individual test conditions. Charging processes can also be simulated well with the model. The resulting voltage deviation is between $-1 \%$ and $0 \%$ for almost all test conditions, only at very low temperatures the deviation shifts somewhat into the positive range. The deviation is thus exactly opposite to the simulation of the discharges, where the deviation for most test conditions is in the positive range. Accordingly, again, a somewhat too low parameterized loss mechanism appears, which leads to a too low overvoltage in both charge and discharge. This is also shown in the simulations of the charge process, where the model results in a slightly too high capacity. However, the numerous

Table III. Differences of the extractable capacity between simulations and measurements of discharges at different ambient temperatures and current rates.

\begin{tabular}{cccccccc} 
& $-10^{\circ} \mathrm{C}$ & $0^{\circ} \mathrm{C}$ & $10^{\circ} \mathrm{C}$ & $20^{\circ} \mathrm{C}$ & $25^{\circ} \mathrm{C}$ & $30^{\circ} \mathrm{C}$ & $40^{\circ} \mathrm{C}$ \\
\hline $1 \mathrm{C}$ & $4.5 \%$ & $6.4 \%$ & $5.8 \%$ & $3.0 \%$ & $1.8 \%$ & $1.1 \%$ & $0.7 \%$ \\
$2 \mathrm{C}$ & $2.5 \%$ & $4.3 \%$ & $4.5 \%$ & $3.3 \%$ & $2.3 \%$ & $1.5 \%$ & $0.9 \%$ \\
$3 \mathrm{C}$ & $2.1 \%$ & $3.4 \%$ & $3.7 \%$ & $2.9 \%$ & $2.7 \%$ & $1.7 \%$ & $1.7 \%$ \\
$5 \mathrm{C}$ & $2.0 \%$ & $2.4 \%$ & $2.6 \%$ & $2.0 \%$ & $2.1 \%$ & $1.7 \%$ & $1.9 \%$
\end{tabular}

feedback loops within the model make it difficult to assign deviations to a specific process.

Pulse tests are used to check the dynamic characteristics of the model. These were recorded at temperatures between $-10^{\circ} \mathrm{C}$ and $40^{\circ} \mathrm{C}$ and contain $10 \mathrm{~s}$ and $100 \mathrm{~s}$ long pulses with up to $5 \mathrm{C}$ at four different states of charge. A comparison of the voltage profile for the test at $25^{\circ} \mathrm{C}$ ambient temperature is shown in Figure 9. For better comparison of the individual pulses, the maximum/minimum voltages in the pulses are marked by circles and crosses. A good correspondence between simulation and measurement is shown for all current rates at both pulse lengths. Due to the short pulses, only small concentration gradients are formed in the electrolyte and the active material, the voltage response is largely based on the purely ohmic resistance and the charge transfer. Thus, the matching indicates a suitable parameterization of the ohmic resistance of the battery by the current collector and contact resistance as well as the electrolyte resistance and the charge transfer resistance. The comparison between simulated and measured voltage for all four ambient temperatures tested is shown in section S.6 of the supplementary material.

A further comparison uses the recorded impedance spectra. The impedance spectra are simulated analogously to a normal measurement. Alternating currents with different frequencies are generated as input profiles and the voltage simulated therefrom is evaluated. This is done for several frequencies. In Figure 10, the simulation as well as the measured values of an impedance spectrum are shown at $25^{\circ} \mathrm{C}$ and $50 \%$ state of charge. The limitations of the impedance calculation with the physico-electrochemical model can be clearly seen. The ohmic resistance of the cell is slightly underestimated, which is reflected in a shift of the entire spectrum. In the high-frequency 


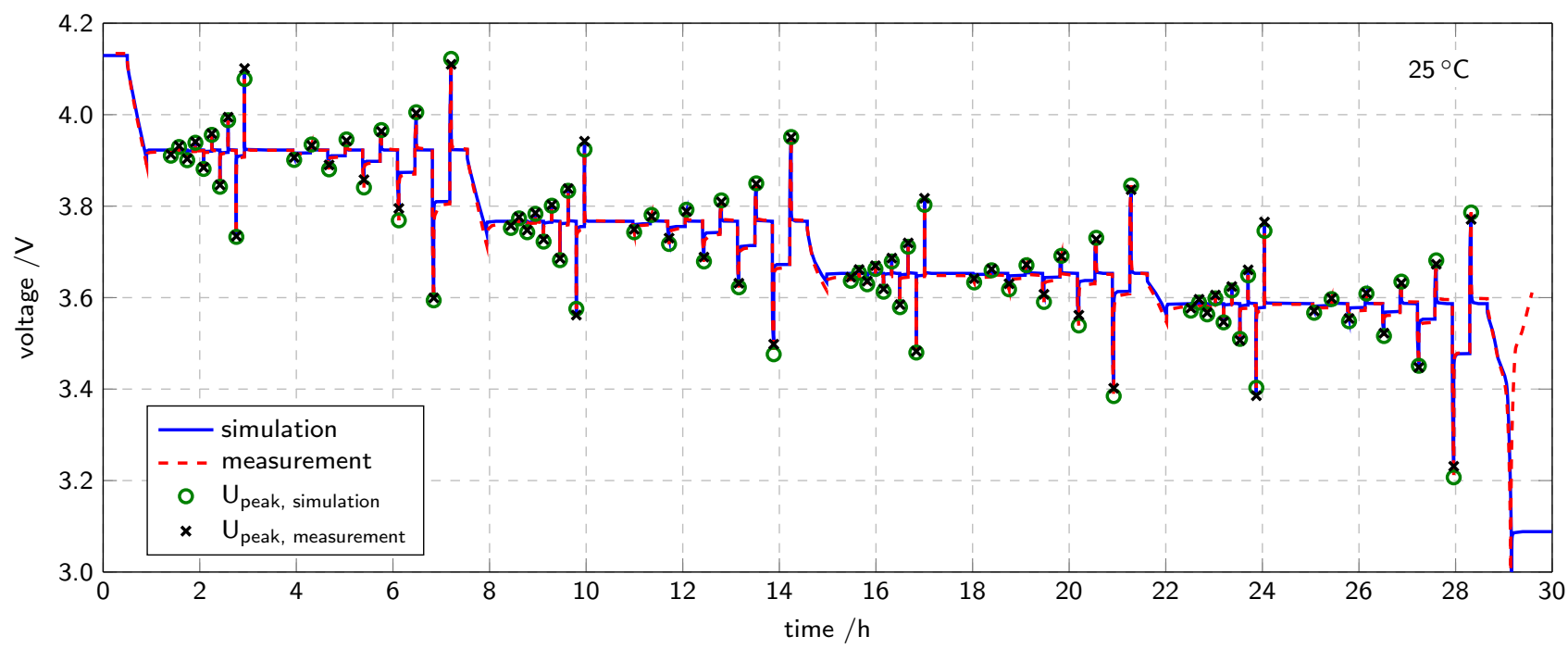

Figure 9. Comparison of the measured and simulated voltage for an ambient temperature of $25^{\circ} \mathrm{C}$ from the pulse tests. For better comparison of the pulses, the maximum/minimum voltages in the pulses are marked by circles and crosses.

range, inductive components are present in the measurement through the cables as well as the internal geometric structure of the cell. These are not implemented in the simulation, also the complex geometry of the cell is replaced by two planar electrodes in the model. The medium-frequency range with the charge transfer semicircle shows quite good agreement. The size of the half-circle is reproduced well, whereby the influence of the porous structure at higher frequencies in the measurement is largely covered by the inductive components. In the frequency representation, there is also a slight shift in the charge transfer half-circle toward higher frequencies. The low-frequency diffusion behavior, in turn, shows significant deviations between model and measurement. The comparison of further simulations and measurements of impedance spectra at different temperatures and charge states is shown in section S.7 of the supplementary material.

After validations by synthetic profiles, a realistic driving profile is also tested in order to demonstrate the applicability for real applications. The profile is from a test drive that has been scaled to a single cell. The comparison between simulated and measured voltage as well as the voltage deviation are shown in Figure 11. Again, a shift of the simulated versus the measured voltage is shown. The voltage deviation is for the most part between $0 \%$ and $1 \%$, with some peaks above and below. Overall, the slight deviation already present in the pure discharge is shown during the realistic profile because of a somewhat too low overvoltage. Comparisons for all four ambient temperatures tested are given in section S.8 of the supplementary material.

\section{Conclusions}

In the first part of this publication ${ }^{14}$ the physical and electrochemical parameters for a $28 \mathrm{Ah}$ PHEV cell were determined. As the cell shows a significant self-heating, in this second part of the publication a thermal model as extension to the physico-chemical model was proposed. In addition, the thermal properties of the cell were analyzed. All measured parameters together with few data from literature are summarized in Table II. The validation was done with this parameter set.

For the validation a wide range of measurements were done. Full discharge and charge curves were recorded from $1 \mathrm{C}$ to $5 \mathrm{C}$ and $0.25 \mathrm{C}$ to $2 \mathrm{C}$ at temperatures from $-10^{\circ} \mathrm{C}$ to $40^{\circ} \mathrm{C}$ to allow a detailed comparison with simulation results. For the dynamic behavior pulse tests with different pulse currents, pulse lengths and temperatures were performed, together with a realistic driving profile. Also EIS measurements were done for various SOC and temperature conditions.
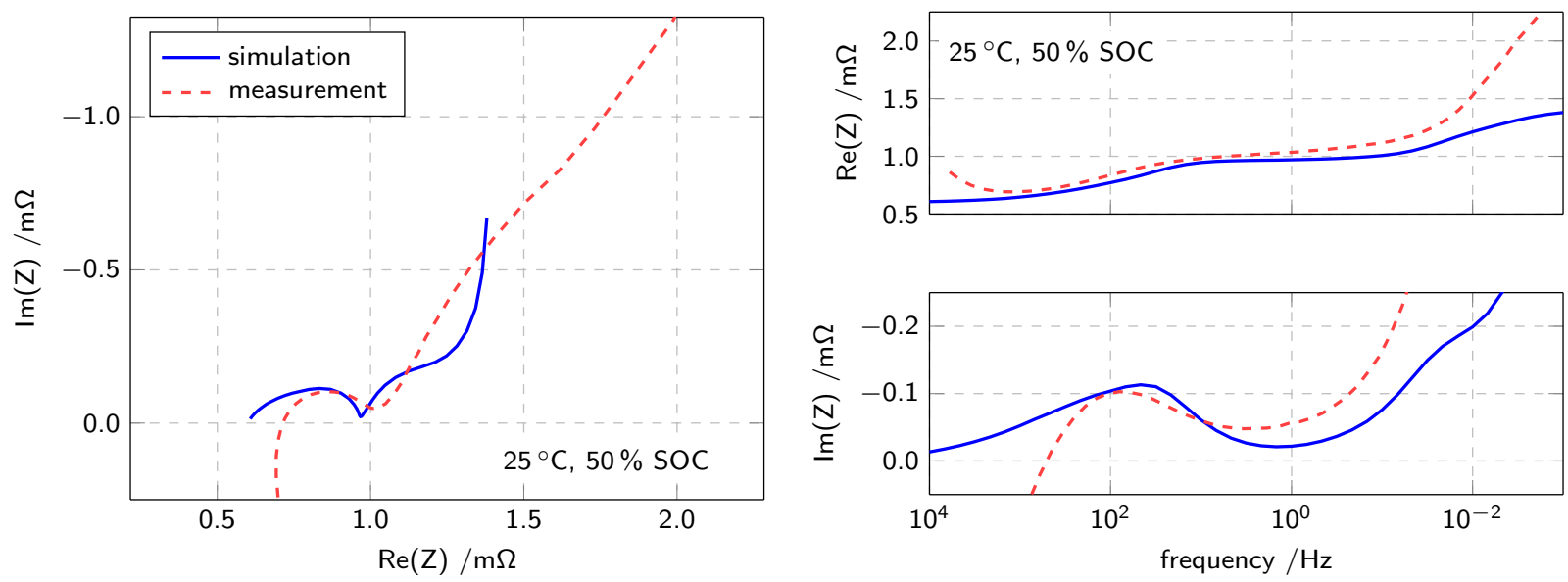

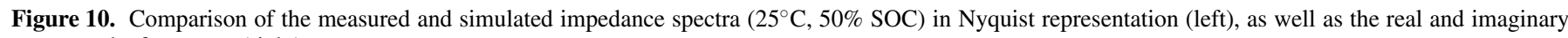
part over the frequency (right). 

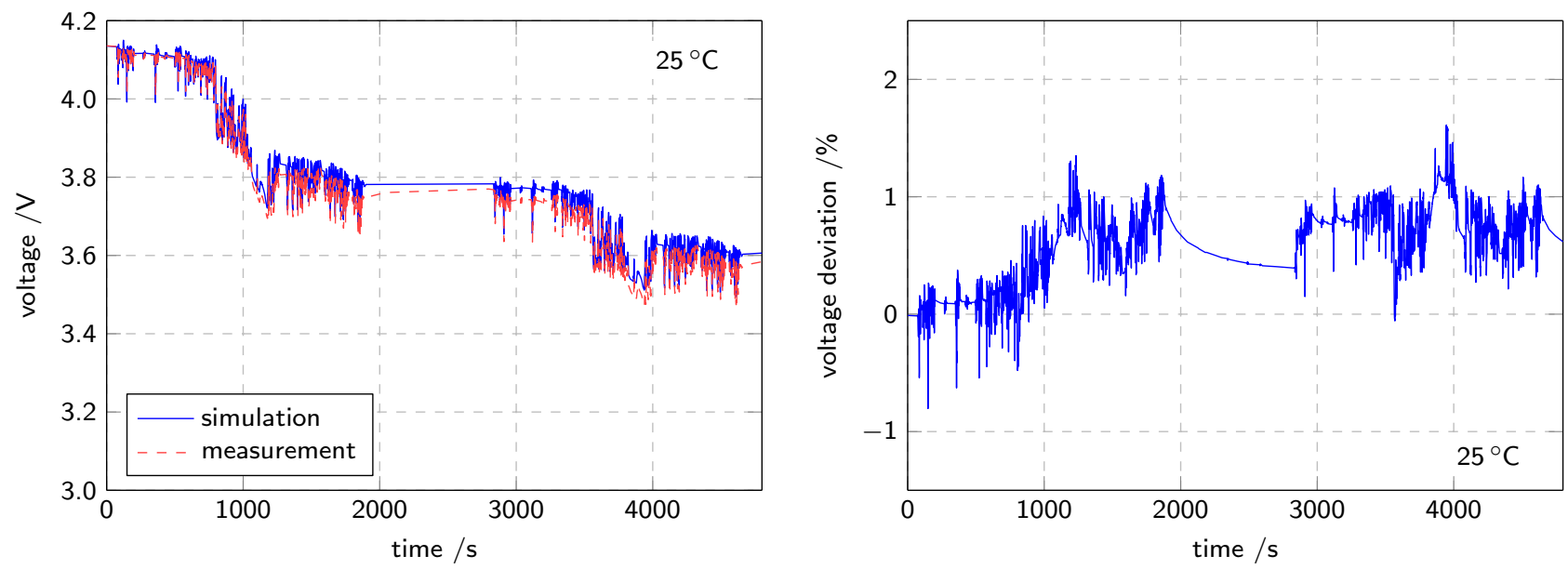

Figure 11. Comparison of the measured and simulated voltage (left) as well as the voltage deviation (right) from the realistic driving profile.

The simulations were done with a Newman-style model. The validation showed a good agreement between the simulation results and the measured values over the complete tested temperature range. It could thus be shown that the behavior of the full cell can be reproduced in small error limits purely from the parameterization of individual material parameters. This applies both to the synthetic profiles as well as to the realistic driving profile. For example, the voltage during discharge and charge cycles could be simulated with an voltage deviation of only $\pm 1.5 \%$. Larger deviations showed up while simulating impedance spectra, this might be due to an oversimplification of the cell with the Newman-model.

These results show that the parameter extraction from commercial lithium-ion batteries is possible and leads to models that can accurately describe these cells. Together with the first part of this publication, a complete parameterization procedure is given. The thus parameterized physico-chemical model can be used for the optimization of cell production or to predict the internal states such as the locale anode potential. This can be used for better understanding of aging processes or safe implementations of fast charging protocols that prevent lithium-plating.

\section{Acknowledgments}

This work has been done during the time as an associated member of the research training group 'mobilEM' (GRK 1856/1). The model was developed and used in the project MEET-HiEnD (03X4634B). The authors thank the Federal Ministry of Education and Research $(\mathrm{BMBF})$ for funding. The authors also thank Fabian Frie, Rita Graff, Izaro Laresgoiti, Meinert Lewerenz, Jens Münnix, Jan-Hendrik Schöbel and Alexander Warnecke for the measurements done within this parameterization and Moritz Teuber for proofreading.

\section{ORCID}

Johannes Schmalstieg (D) https://orcid.org/0000-0002-0695-6762

\section{References}

1. J. Newman and W. Tiedemann, Porous-Electrode Theory with Battery Applications, AIChE Journal, 21(1), 25 (1975).

2. P. Ramadass, B. Haran, P. M. Gomadam, R. White, and B. N. Popov, Development of First Principles Capacity Fade Model for Li-Ion Cells, Journal of The Electrochemical Society, 151(2), A196 (2004).
3. J. Christensen and J. Newman, A Mathematical Model for the Lithium-Ion Negative Electrode Solid Electrolyte Interphase, Journal of The Electrochemical Society, 151(11), A1977 (2004)

4. P. Arora, M. Doyle, and R. E. White, Mathematical modeling of the lithium deposition overcharge reaction in lithium-ion batteries using carbon-based negative electrodes, Journal of The Electrochemical Society, 146(10), 3543 (1999).

5. I. Laresgoiti, S. Käbitz, M. Ecker, and D. U. Sauer, Modeling mechanical degradation in lithium ion batteries during cycling: Solid electrolyte interphase fracture, Journal of Power Sources, 300, 112 (2015).

6. I. J. Ong, Double-Layer Capacitance in a Dual Lithium Ion Insertion Cell, Journal of The Electrochemical Society, 146(12), 4360 (1999).

7. M. Doyle, J. P. Meyers, and J. Newman, Computer Simulations of the Impedance Response of Lithium Rechargeable Batteries, Journal of The Electrochemical Society, 147(1), 99 (2000).

8. R. Darling and J. Newman, Modeling a Porous Intercalation Electrode with Two Characteristic Particle Sizes, Journal of The Electrochemical Society, 144(12), 4201 (1997).

9. P. Albertus, J. Christensen, and J. Newman, Experiments on and Modeling of Positive Electrodes with Multiple Active Materials for Lithium-Ion Batteries, Journal of The Electrochemical Society, 156(7), A606 (2009).

10. M. Tang, P. Albertus, and J. Newman, Two-Dimensional Modeling of Lithium Deposition during Cell Charging, Journal of The Electrochemical Society, 156(5), A390 (2009).

11. M. Ecker, T. Tran, P. Dechent, S. Käbitz, A. Warnecke, and D. Sauer, Parameterization of a Physico-Chemical Model of a Lithium-Ion Battery: I. Determination of Parameters, Journal of The Electrochemical Society, 162(9), A1836 (2015).

12. M. Ecker, S. Käbitz, I. Laresgoiti, and D. U. Sauer, Parameterization of a PhysicoChemical Model of a Lithium-Ion Battery: II, Model Validation, Journal of The Electrochemical Society, 162, A1849 (2015).

13. J. Schmalstieg, Physikalisch-elektrochemische Simulation von Lithium-IonenBatterien: Implementierung, Parametrierung und Anwendung, PhD thesis, RWTH Aachen University, Aachen (2017).

14. J. Schmalstieg, C. Rahe, M. Ecker, and D. U. Sauer, Full Cell Parameterization of a High-Power Lithium-Ion Battery for a Physico-Chemical Model: Part I. Parameter Determination, Journal of The Electrochemical Society, 165 (16), A3799 (2018).

15. L. Cai and R. E. White, Mathematical modeling of a lithium ion battery with thermal effects in COMSOL Inc. Multiphysics (MP) software, Journal of Power Sources, 196(14), 5985 (2011).

16. S. Tippmann, D. Walper, L. Balboa, B. Spier, and W. G. Bessler, Low-temperature charging of lithium-ion cells part I: Electrochemical modeling and experimental investigation of degradation behavior, Journal of Power Sources, 252, 305 (2014).

17. J. P. Schmidt, S. Arnold, A. Loges, D. Werner, T. Wetzel, and E. Ivers-Tiffée, Measurement of the internal cell temperature via impedance: Evaluation and application of a new method, Journal of Power Sources, 243, 110 (2013).

18. H. Lundgren, P. Svens, H. Ekström, C. Tengstedt, J. Lindström, M. Behm, and G. Lindbergh, Thermal Management of Large-Format Prismatic Lithium-Ion Battery in PHEV Application, Journal of The Electrochemical Society, 163(2), A309 (2016).

19. M. Ender, Mikrostrukturelle Charakterisierung; Modellentwicklung und Simulation poröser Elektroden für Lithiumionenzellen, PhD thesis, KIT (2014).

20. M. Ender, A. Weber, and E. Ivers-Tiffée, A novel method for measuring the effective conductivity and the contact resistance of porous electrodes for lithium-ion batteries, Electrochemistry Communications, 34, 130 (2013). 